\title{
Ayurveda and Lifestyle Modification: Research to Practice
}

\author{
Kaushik Chattopadhyay
}

\section{Kaushik Chattopadhyay}

Assistant Professor (Evidence-based Healthcare), Division of Epidemiology and Public Health, School of Medicine, The University of Nottingham, Nottingham, UK.

\section{Correspondence}

\section{Dr. Kaushik Chattopadhyay}

Assistant Professor (Evidence-based Healthcare), Division of Epidemiology and Public Health, School of Medicine, The University of Nottingham, Nottingham, UK.

Email: kaushik.chattopadhyay@nottingham.ac.uk

\section{History}

- Submission Date: 05-06-2017

- Accepted Date: 15-06-2017

DOI : 10.5530/ijmedph.2017.3.27

Article Available online

http://www.ijmedph.org/v7/i3

\section{Copyright}

(C) 2017 Phcog.Net. This is an openaccess article distributed under the terms of the Creative Commons Attribution 4.0 International license.

\begin{abstract}
The global burden of non-communicable diseases is rapidly increasing, and the essential management strategy is to follow a healthy lifestyle. Ayurveda can play a major role in this aspect, as the primary aim of Ayurveda is to prevent diseases by following a healthy lifestyle. However, in order to implement such classical knowledge (that is, healthy lifestyle based on Ayurvedic principles) into real practice, a systematic process needs to be followed. This systematic process must include robust research studies (that is, development and evaluation of Ayurveda-based lifestyle intervention) and behaviour change of people. This paper describes these two important steps in detail. In conclusion, there is a huge scope of implementing classical Ayurvedic knowledge into real practice, which will be beneficial to all of the society. Key words: Ayurveda, Healthy lifestyle, Research, Evidence-based, Behaviour change.
\end{abstract}

\section{INTRODUCTION}

Globally, there is a huge burden of non-communicable diseases (NCDs), such as cardiovascular diseases, cancers, respiratory diseases and diabetes. Around 55\% of all cause disability-adjusted life years (DALYs), ${ }^{1 \text { a }}$ a summary measure to indicate the overall burden of disease and includes mortality as well as morbidity, are due to NCDs. ${ }^{1}$ Modifiable lifestyle factors, such as physical inactivity and unhealthy diets, are some of the important risk factors of NCDs and thus, the essential management strategy is to follow a healthy lifestyle, including diet. ${ }^{2}$ However, the conventional or western care model has its own limitations in terms of its effectiveness, safety, affordability and acceptability. ${ }^{3}$ Ayurveda, a system of medicine that originated in the Indian subcontinent, can play a major role in this aspect. The primary aim of Ayurveda is to prevent diseases by following a healthy lifestyle. ${ }^{4}$ Ayurvedic approach to a healthy lifestyle arya (night-time regimen) and ritucharya (seasonal regimen), and these have been described in detail in various classical Ayurvedic texts (such as texts written by Charaka (400-200 BC), Sushruta (400-200 BC) and Vagbhatt (600-500 BC) ${ }^{4-6}$ However, in order to implement such classical knowledge (that is, healthy lifestyle based on Ayurvedic principles) into real practice, a systematic process needs to be followed. This systematic process must include robust research studies and behaviour change of people. includes dinacharya (day-time regimen), ratrich-

\section{STEP ONE: DEVELOPMENT AND EVALUATION OF AYURVEDA- BASED LIFESTYLE INTERVENTION}

The evidence-base of Ayurveda related studies is extremely poor, which is either due to the non-existence of research studies or poorly conducted research studies. ${ }^{7}$ The first step should be to develop an Ayurveda-based lifestyle intervention and then, to evaluate its effectiveness, safety, affordability and acceptability. Globally, the United Kingdom Medical Research Council's guideline is used for development and evaluation of complex interventions. ${ }^{8}$ This guideline should be used to develop and evaluate Ayurveda-based lifestyle interventions, which are considered to be complex. It should be noted that this is an iterative process, as shown in Figure 1, and mixed methods approach (quantitative (including economic evaluation) as well as qualitative) should be used. ${ }^{8}$ Apart from this guideline, many internationally recognised checklists, to report research studies, are available which could be used to design such studies, such as the Consolidated Standards of Reporting Trials (CONSORT) 2010 (includes a specific checklist for herbal medicines) and Drummond's checklist for assessing economic evaluation studies. ${ }^{9-14}$

\section{STEP TWO: BEHAVIOUR CHANGE}

The availability of a lifestyle intervention and providing health education are not enough to bring the desired outcomes in people. ${ }^{15,16}$ Once the Ayurveda-
Cite this article : Chattopadhyay K. Ayurveda and Lifestyle Modification: Research to Practice. Int J Med Public Health. 2017;7(3):132-3. 


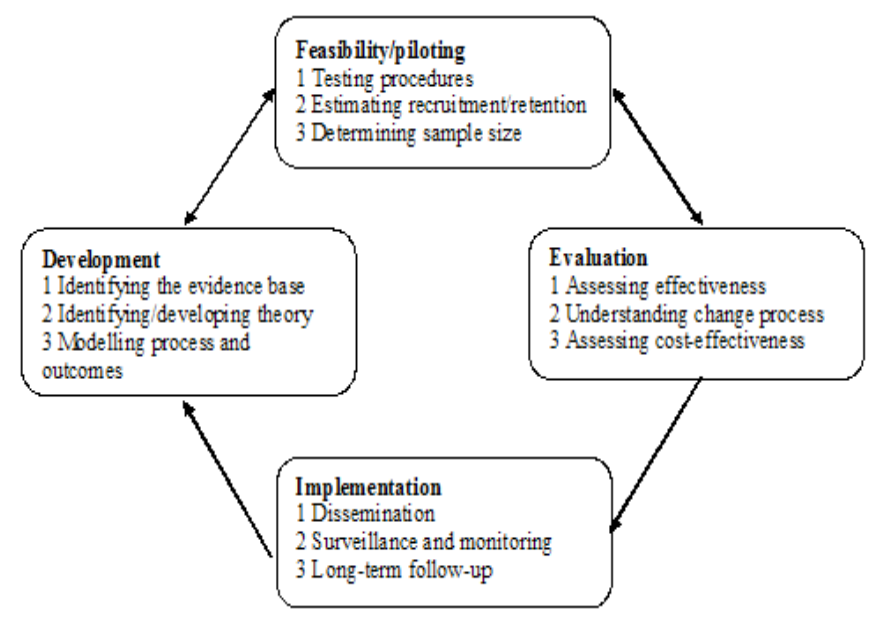

Figure 1: Key elements of the development and evaluation process ${ }^{8}$

based lifestyle intervention is developed and is found to be effective, safe, affordable and acceptable, then this intervention needs to be implemented in real practice through the behaviour change of people. A behaviour emerges from the interaction between three necessary conditions: capability (psychological or physical ability to enact the behaviour), motivation (reflective and automatic mechanisms that activate or inhibit the behaviour) and opportunity (a physical and social environment that enables the behaviour). ${ }^{17,18}$ The behaviour change process helps an individual to transit from an unhealthy lifestyle to a healthy lifestyle and to adhere to the healthy lifestyle in the longer term. ${ }^{15,16}$ The established behaviour change techniques (BCTs), such as information provision, exploration and reinforcement of motivation to change, goal setting, action planning, coping plans, and relapse prevention, should be used for this purpose. ${ }^{16}$ The selection and application of any additional BCT should be based on the behavioural analysis, that is, by understanding the target behaviour. ${ }^{17,18}$ The main questions involved in this process are: why the desired behaviour is not occurring and what needs to change for the desired behaviour to occur? The theoretical domains framework (TDF), as shown in Figure 2, can help to understand the target behaviour and answer these questions. ${ }^{17,18}$

\section{CONCLUSION}

There is a huge scope of implementing classical knowledge (that is, healthy lifestyle based on Ayurvedic principles) into real practice, which will be beneficial to all of the society. This implementation of classical Ayurvedic knowledge should follow a systematic process, which must include robust research studies and behaviour change of people.

\section{CONFLICT OF INTEREST}

None

\section{REFERENCES}

1. World Health Organisation (WHO). Disability-adjusted life years (DALYs). Global Health Observatory (GHO) data. Geneva, Switzerland:WHO. 2012. http://www. who.int/gho/mortality_burden_disease/daly_rates/text/en/ Accessed it on 29 April 2016.

2. WHO. Non-communicable diseases (NCD). GHO data. Geneva, Switzerland: WHO. 2016. http://www.who.int/gho/ncd/en/ Accessed it on 29 April 2016.

\begin{tabular}{|l|l|}
\hline Soc & Social influences \\
\hline Env & Environmental context and resources \\
\hline Id & Social professional role and identity \\
\hline Bel Cap & Beliefs about capabilities \\
\hline Opt & Optimism \\
\hline Int & Intentions \\
\hline Goals & Goals \\
\hline Bel Cons & Beliefs about consequences \\
\hline Reinf & Reinforcement \\
\hline Em & Emotion \\
\hline Know & Knowledge \\
\hline Cog & Cognitive and interpersonal skills \\
\hline Mem & $\begin{array}{l}\text { Memory, attention and decision } \\
\text { processes }\end{array}$ \\
\hline Beh Reg & Behavioural regulation \\
\hline Phys & Physical skills \\
\hline
\end{tabular}

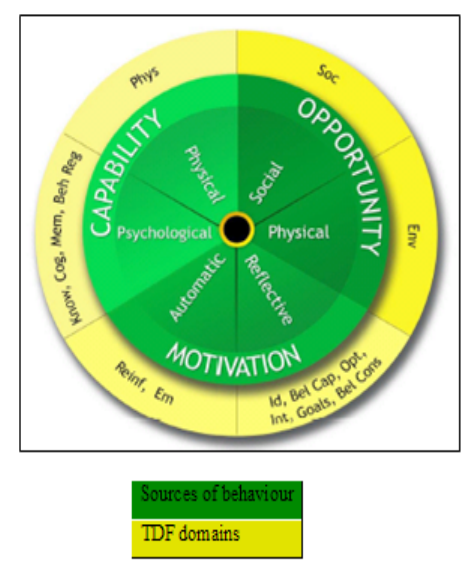

Figure 2: Theoretical domains framework ${ }^{18}$

3. Ernst E. Complementary and alternative medicine. In Oxford textbook of medicine. Edited by Warrell DA, Cox TM, Firth JD. Fifth edition. New York, USA: Oxford University Press. 2010.

4. Charaka. Charaka samhita. 400-200 BC. Translated in English by Sharma PV. Varanasi, India: Choukhamba Orientalia. 1981.

5. Sushruta. Sushruta samhita. 400-200 BC. Translated in English by Bhishagratna KL. Varanasi, India: Choukhamba Orientalia. 1991.

6. Vagbhatt. Astanga hridaya. 600-500 BC. Translated in English by Murthy S. Varanasi, India: Choukhamba Orientalia. 1991.

7. Patwardhan B. Bridging Ayurveda with evidence-based scientific approaches in medicine. EPMA J. 2014;5(1):19.

8. Medical Research Council (MRC). Developing and evaluating complex interventions: New guidance. London, UK: MRC. 2008.

9. Schulz KF, Altman DG, Moher D, CONSORT Group. CONSORT 2010 statement: Updated guidelines for reporting parallel group randomised trials. BMJ. 2010;340:c332.

10. Moher D, Hopewell S, Schulz KF, Montori V, Gøtzsche PC, Devereaux PJ, et al. CONSORT 2010 explanation and elaboration: Updated guidelines for reporting parallel group randomised trials. BMJ. 2010;340:c869.

11. Gagnier JJ, Boon H, Rochon P, Moher D, Barnes J, Bombardier C, et al. Reporting randomised, controlled trials of herbal interventions: An elaborated CONSORT statement. Ann Intern Med. 2006;144(5):364-7.

12. Gagnier J, Boon H, Rochon P, Barnes J, Moher D, Bombardier C, et al. Improving the quality of reporting of randomised controlled trials evaluating herbal interventions: Implementing the CONSORT statement [corrected]. Explore (NY). 2006;2(2):143-9

13. Gagnier JJ, Boon H, Rochon P, Moher D, Barnes J, Bombardier C, et al. Recommendations for reporting randomised controlled trials of herbal interventions: Explanation and elaboration. J Clin Epidemiol. 2006;59(11):1134-49.

14. Drummond MF, Jefferson TO. Guidelines for authors and peer reviewers of economic submissions to the BMJ. The BMJ Economic Evaluation Working Party. BMJ 1996;313(7052):275-83.

15. National Cancer Institute. Theory at a glance: A guide for health promotion practice. Second edition. Bethesda, USA: National Institutes of Health. US Department of Health and Human Services. 2005.

16. National Institute for Health and Care Excellence (NICE). Behaviour change: General approaches. NICE public health guidance 6. Manchester, UK: NICE. 2007.

17. Michie S, Van Stralen MM, West R. The behaviour change wheel: A new method for characterising and designing behaviour change interventions. Implement Sci. $2011 ; 6(1): 42$

18. Cane J, O'Connor D, Michie S. Validation of the theoretical domains framework for use in behaviour change and implementation research. Implement Sci. $2012 ; 7(1): 37$.

Cite this article : Chattopadhyay K. Ayurveda and Lifestyle Modification: Research to Practice. Int J Med Public Health. 2017;7(3):132-3. 